Rosie Cox

\title{
Competitive Mothering and Delegated Care: Class Relationships in Nanny and Au Pair Employment
}

\section{Introduction}

The last two decades appear to have been a time of growth for nanny and au pair employment in Europe, the USA and Canada (Cox 2006, Lutz 2008, Macdonald 2010, Widding-Iskasen 2010). This growth is commonly explained as being due to changes in women's work outside the home, particularly the increasing numbers of middle class women who now work in career structured jobs which demand long hours and commitment (Gregson and Lowe 1994). However, while attention to such trends and to changes in women's lives is important, it is also worthwhile being sceptical of explanations which appear to assume that childcare would or should 'normally' be carried out by mothers. Citing the growth in women's paid employment as a reason why more nannies and au pairs are needed denies all the other possible arrangements for childcare that could be made. It silences questions about why men do not do more, why working patterns are so family unfriendly and who cares for the children of families who cannot pay others. In order to better understand the growth in paid childcare in private homes, and to understand variations between countries, and the specific arrangements that families make, it is necessary to also consider attitudes towards childcare (see Williams and Gavanas 2008), ideologies around mothering, and the rise of competitive caring in an increasingly neoliberalised world.

Childcare is not just about keeping children safe, fed and watered, but it is also about social reproduction. Increasingly, for middle class families, this entails ensuring children's advantages in what is perceived to be a competitive environment. Opting for individualised care, rather than a form of communal care, becomes part of parenting strategies which are about passing on cultural capital and preparing children to succeed.

In this paper I explore how, in such a competitive environment, the mothering projects of nanny and au pair employers and the carers they employ become inter-twined and yet may also be in conflict or competition. I make two arguments about the inter-twining of current practices of competitive mothering and the employment of nannies and au pairs. First, practices of competitive mothering can underpin the demand for paid, privatized care in the home (such as nannies and au pairs) and involve middle class/advantaged women using 
their position to raise their children in ways which are specifically designed to ensure and enhance their children's future social status and income. This can be at the cost of the mothering projects (and children) of the women they employ. Second, one factor which underlies the prevalence of competitive mothering within certain middle class families is the conflict that working mothers feel about their roles, and their strong desire to address these conflicts by showing that their children do not suffer because of their employment. The emphasis on care for children as mothering, rather than parenting - or better still 'care' underpins this sense of conflict. The idea that it is mothers who are delegating care, rather than parents or society at large, is an important element in the organisation of care, and the relationships with carers that ensue.

To make these arguments I draw on Cameron Lynne Macdonald's (2010) work on 'Shadow Mothers' and the work of Joan Tronto on care ethics (1993), particularly her concept of 'competitive care' (2006). The paper starts by outlining what 'competitive mothering' is and how it underpins demands for individualised childcare, done by carers with particular characteristics. I then look at the idea of 'doing the best' for your children as a hegemonic idea, a mantra that is so pervasive it remains almost unnoticed and unanalysed, and which can be used to justify any form of behaviour whilst actually reinforcing existing inequalities. I then look at the specific effects these ideas of competitive mothering and 'doing the best' for children have on childcare workers and how they frustrate workers' own parenting projects, before reflecting on the need to re-think care and who is responsible for it, in order to address these inequalities.

\section{Ideologies of competitive mothering: 'They should wash our feet and drink the water...'}

Cameron Lynne Macdonald (2010 p.64) reports that a nanny she interviewed commented about employers: ' $\mathrm{t}]$ hey should wash our feet and drink the water for how they get ahead at our expense, and we fall behind.' In this section I examine how this happens - how class advantage is played out within and through the employment of privatized in-home childcare and practices of 'competitive mothering' that enable employers, and their children, to get ahead at the expense of childcarers, and their children.

Macdonald (2010) describes 'competitive mothering' as an ideology which supports the idea that each family, or more specifically, each mother, is expected to transmit the economic, social and cultural resources needed to maintain or enhance a child's class status. 
Childrearing strategies which give one's child a competitive edge are, therefore, particularly important to middle class and upper-middle class families.

Competitive mothering is closely related to ideas of intensive mothering and the 'perfectible child' which are popular in child-rearing manuals consumed by middle class mothers. These manuals put forward the idea that children benefit from 'intensive mothering' in the first three years of life, that there is a unique and special bond between mother and child ${ }^{\mathrm{i}}$. Additionally, if enough attention, effort and correct mothering is invested, children are 'perfectible'. That is, they could be made smarter, happier and better adjusted. Any short fall in children's happiness or accomplishments (at any point in their future lives) is, therefore, evidence of a mother's failure.

Macdonald is commenting on the USA, but the UK situation is similar, although perhaps not quite as extreme. Both countries are characterised by ideologies of individualism and an increasing privatisation of care responsibilities. Both have strong ideologies which favour 'motherlike' care as best for children (Gregson and Lowe 1994) and which see communal care as second-rate compared to individualised childcare in the home. It is important to note that these preferences for individualised care are not universal, but are place-specific and reflect the 'care cultures' which dominate in a country (Williams and Gavanas 2008). Care cultures are 'dominant local and national discourses on what constitutes appropriate childcare [...] National variations in care cultures may also be cut across by subnational differences of class, ethnicity and location' (Williams and Gavanas 2008 p.15 -16). Related to care cultures are 'childcare regimes' which are the institutional policies, practices and policy logics which govern childcare. While the childcare regimes of Nordic countries have favoured the provision of public childcare, provided by the state, the ideologies of the USA and UK underpin demand for paid domestic workers, such as nannies and au pairs.

Doing the best for your children or fuelling vicious circles of privatised care? The logic that underpins competitive mothering is closely related to the idea of 'doing what is best' for children. In an unequal world these practices can only lead to more inequality and they create conditions that encourage employers and their children to get ahead at the cost of childcare workers and their children. 'Doing the best' for one's children is a motivation which, has become a new mantra, an excuse that can be used to explain (and forgive) any form of behaviour, be it lying about a religious affiliation to get a place in a church school, or playing the welfare system in order to buy toys and gadgets. Even City bankers, interviewed 
after the 2008 banking crisis, explained their behaviour in these terms. They asked for understanding of their quests for ever bigger bonuses. They were not greedy, they said, but rather they just wanted to do the best for their children by providing private education, extra activities and all the good things money can buy. Even destroying the world economy is justifiable, it seems, if you do so for the good of your children.

The language of 'doing the best' is so common it is easy not to notice, and explanations based on this claim get their strength from the implication that such behaviour is natural, and anyone not 'doing the best' for their children would be a bad parent and, probably, a bad person. However, what is right for children is not necessarily about enabling them to compete most successfully (i.e. make money). These are socially specific values. In a different time or place parents might think it was more important to provide an example of good behaviour or pass on moral values.

Joan Tronto has written extensively on the ethics of care (1993) and the undervaluing of care work (see 2002, 2011 for example). Her work is instructive in illuminating the way that 'doing the best' for one's children is necessarily caught up in broader processes of social inequality. She uses the concept of 'competitive caring' to explain that while care remains a subordinate value and activity within a competitive society, caring well for your family necessarily 'will make one an enemy not a friend of equal opportunity', she continues:

In a competitive society what it means to care well for one's own children is to make sure they have a competitive edge against other children. On the most concrete level, while parents may endorse a principle of equality of opportunity in the abstract, their daily activities are most visibly "caring" when they gain special privileges and advantages for their children (2006 p.10).

Far from being in some way separate from or outside the norms of capitalist, market relationships, care at home is shaped by them both directly and indirectly. This is not only in the most obvious ways, such as the pay and working conditions of childcare workers, but also in less obvious ways- such as what it means to provide care. The competitive mothering projects of middle class childcare employers produce advantage for their own children (and themselves) at the cost of other children, including those of the workers they employ.

\section{So what does this mean for those doing the care? The people who 'fall behind'?}

In this section I explore the direct effects this approach has on childcare workers. Time, resources and energy are expended on the children of the wealthy in ways that detract from those doing the care and their children. This is not an argument about 'care extraction', a 
concept that arises in the global care chains literature (Hochschild 2003) and which suggests that through the employment of migrant childcare workers, love is extracted from poorer countries and used by the wealthiest families in the wealthiest countries. Whilst this image has great force and is important in directing attention to the emotional costs of migration for lowpaid migrant workers and their families, I also think the argument can be problematic. It relies in part on limited assumptions about what it means to care for one's children. Privileged white men, for example, are seen to care for their children by providing economically, when poorer, darker women do the same thing it is seen as uncaring (see also Parreñas 2001, McKay 2007, Miller and Madianou 2011).

The families of childcare workers and the workers themselves can be disadvantaged in many ways by their work, including through long and unpredictable working hours, low pay and exhausting work. Childcare workers in private homes tend to be subject to particularly long and often highly 'flexible' hours of work. This is because their working day has to encompass the entirety of their employer's work hours, plus their travel time, plus any handover time. Nannies are often employed by families in which both parents work long hours and have strong commitments to work, precisely because they are available for more hours than communal childcare would be and can be called at short notice and asked to cover if a meeting runs over or there is a deadline the employer needs to meet. It is not unusual for a nanny's working day to start at 7am and run until 6 or $7 \mathrm{pm}$. For nannies who live in, the day may be longer still, including babysitting in the evening and getting up at night if children wake. Nannies who live out may still be expected to be 'flexible' about working hours and will often be expected to prioritise their employer's need to stay at work over any demands they may have from their own home lives. The long hours in the office for employers lead to success and promotion but for those doing childcare they generally mean time away from family and friends with little thanks and rarely much additional reward.

The pay of childcarers is also directly affected by the pay of their employers. When working out what they are prepared to pay for childcare most families consider how much the family member who has been doing childcare could earn in the time available if they were freed of their childcare responsibilities. The childcare then has to fit within this amount, with enough left over for the family member not to feel like she is 'working for nothing'. It is almost always the mother who is considered to be replaced by the paid carer both because women are considered to be primary carers and are likely to be out of the workforce on maternity leave or on a longer break when these calculations are being made, and because on 
average women earn less than men and are seen as taking less out of the household if they give up work to care for children ${ }^{\mathrm{ii}}$ (Cox 2006). The assumptions underlying the calculations of individual families are devastating to the value placed on care work. Care is only seen as worth paying for if it costs less than another person's earnings. Additionally, care worker's pay has to be held below not just average pay, but women's pay - which is already lower than the combined male and female average. So the logic underpinning childcare in private homes means that it is organised so that care workers almost always work longer hours than their employers for less pay.

Low pay, long hours and exhausting work mean that childcarers who are parents too are often unable to do the sorts of activities with their own children that they do with their employers' children. Nannies may not always agree with the form of mothering that their employers favour (Hondagneu-Sotelo 2001) but some do want to be able to provide their own children with the sorts of opportunities and activities that they are paid to introduce their charges to (Macdonald 2010). Nannies who know that such activities are seen by well-off, middle class parents as necessary for their children's success, may be doubly frustrated to see their own children miss out because of the lack of free time and money that are a result of their job.

Other aspects of privatised childcare work, including migration regulations and employer rules, prevent care workers having children at all. In many countries there are specific migration schemes for paid domestic workers and a number of these either prevent workers bringing their children with them, or are only open to people without dependent children (Cox 2011). Domestic workers are often subject to specific visa regimes which construct their status as not quite that of 'workers'. They will often be required to live in, may not have the same rights to minimum wage or maximum working hours as other groups and will rarely have the right to family reunification. The large literature on migrant domestic workers and transnational mothering reveals the emotional cost to workers of being separated from their children (see amongst others Parreñas 2001, Hondagneu-Sotelo 2001).

For others, being a private childcare worker may mean having to delay motherhood. One important barrier to starting a family is the difficulties childcare workers face in performing care for their own children. Employers are often reluctant to allow workers to bring their own children to work, as they think carers will be less focused on the employer's children than their own. The long hours that careworkers face make the use of day care difficult, if not impossible, as does their low pay relative to the costs of care. Living in can 
make establishing and maintaining relationships difficult and employers may actively seek care workers who cannot expend their emotional energy on their own families. As one of Macdonald's interviewees put it when explaining their choice of a European au pair over a local nanny:

[I was] set on European[s] because I wanted them to be part of the family. I felt that with American[s] ... they would, even if they live in, they would tend to go home [on days off], and I needed the person here in the house and have our family as their priority and not their family as their priority (Macdonald 2010 p.61).

Attitudes such as these are not unusual; the idea that a care worker is part of her employer's family can be interpreted to mean that she has no right to a family life of her own. Thus, through the practices of employers and the regulations of visa regimes the mothering projects of people who clearly care about children are frustrated or put aside for the 'good' of the children of more privileged families.

As well as favouring carers who will be absorbed into a family, the quest for a 'mother substitute' who will further a competitive mothering agenda, tends to favour a particular type of worker who will pass on, or instil class advantages. One outcome of this is that class background can be more important for the employability of childcare workers than qualifications or even experience. For example, an analysis of job advertisements for nannies and au pairs in London showed that employers want workers who can speak multiple languages and who are able to play a range of musical instruments. Nannies have to supervise homework, take charges to myriad after school activities and help them to feel at home with high culture in museums and galleries (Busch 2010). An example of such a job advertisement is shown in Box 1 below.

We are looking for a full-time, experienced nanny to look after our bright and lively twin 8 -year old daughters. We live in a great location close to transport links and park. The job will involve a school run to and from Hampstead morning and afternoon each day, so a driver is essential. We are looking for a well educated candidate with excellent English who will be able to supervise homework, spellings and piano practise [sic]. The position will involve light household and nursery duties, including preparing the family supper and some shopping. Other duties would include organising playdates, sports and activities. During school holidays - creative activities, trips to museums, swimming and ice-skating. We are searching for a cheerful nanny who is happy to muck in and has a flexible attitude. You should know North London well and ideally live locally. Competitive salary.

Box 1: An advertisement posted on 'Gumtree', a website popular with those looking for domestic worker or workers, May 2011.

Rosie Cox: Competitive Mothering and Delegated Care: Class Relationships in Nanny and Au Pair Employment

Studies in the Maternal, 3(2), 2011, www.mamsie.bbk.ac.uk 
Nicky Busch (2010) found that employers in London would favour care workers from 'good' families over those who had qualifications or experience and were able to do this because of a supply of highly educated, middle class migrants who were seeking work in London. Macdonald (2010) found that employers wanted childcare workers who would help their children to develop cultural capital so that they could succeed in the future and, as with those in London, this meant favouring certain nationalities over others and favouring background over skills or experience. Mothers interviewed for both pieces of research discussed not wanting their children to pick up 'accents' from childcare workers who sound working class, or in the case of the USA, speak the 'wrong' kind of Spanish and this would be an additional reason for keeping them out of day care. Mothers wanted childcarers who would help their children to listen to classical music, feel at home in museums and mix with the 'right' kind of children on playdates. These attitudes are played out in an already largely unregulated and discriminatory employment arena, and can be very important in shaping who is and who is not able to get work.

\section{Delegating care and mothering competitively}

As the above shows, parental attitudes about the 'right' way to raise children structure the employment conditions and experiences of childcare workers. One very important aspect of the experience of paid childcarers is the guilt that mother/employers can feel about not doing childcare themselves. In this section I look at the relationships between women's assumed responsibility for childcare, the guilt that mothers can feel if they do not do this work themselves and the conditions that pertain when other people are paid to do it.

The particular relations that exist between individual domestic workers and their employers are structured by some of the most profound forces in our society. Gendered ideologies cast childcare as women's work and particularly the work of mothers. Mothers who chose not to do this work (for whatever reason) are often subject to profound feelings of guilt (that they are not 'proper' mothers) as well as feelings of anxiety about the welfare of their children while they are cared for by others - feelings which are fed by the social assumptions that mothers are the most appropriate and safest carers, as well as by a lack of government regulation of the private childcare sector in some countries (see Uttal 2006), and frustrations at their inability to balance home and paid work both practically and emotionally. As Uttal (2006 p223) puts it 'the organization of work, regulatory neglect, and mothering 
ideologies, create a volatile mixture - one whose only predictable outcome is confusion, worry, and doubt for individual parents.'

As Cheever (2003 p.37) states:

We love our children passionately, and for me, at least, leaving them - for a week or even for a day - is the hardest thing I've ever had to do. That makes the person who takes care of them in my absence both indispensable and somehow an agent of separation and doom - much more than a simple employee.

If parents are anxious they can also feel jealous and may act to reduce the attachment that the care worker and child feel for each other, or to take advantage of the worker's feelings to increase workload (Parrenas 2001, Hondagneu-Sotelo 2001, Búriková and Miller 2010, Macdonald 2010). Employers may want domestic workers to care for children as if they were their own, but they do not want those workers to feel as if the children were their own, or for their children to love their carers too much.

Macdonald (2010) argues that the practices of competitive mothering which she found in her research are particularly predominant amongst mother/employers who work full time but who subscribe to the view that childcare is mother's work and any other arrangement such as care by fathers, friends or paid employees is a delegation of a biological role. The outcome is that mother/employers micro-manage their employees, denying them any sense of independence or personhood (for example not allowing nannies to ever leave the house while caring for a baby, or recording each day's activities in detail even for a child who is only a few months old). Macdonald argues that these mothers will also focus on measureable outcomes and goals, such as the age at which a child talks, walks or can read, in order to reassure themselves they are not bad mothers. This focus translates into prioritising their child's competitive advantages as a means by which to measure the success of their parenting strategies.

The burden of believing that childcare is mother-work produces guilt, anxiety and frustration for mothers who do not do such work themselves. It underpins a commitment to competitive mothering strategies which perpetuate social inequality and leads to complicated and often unreasonable relationships with the paid carers who they believe are replacing them.

\section{Conclusions}

The guilt, anxiety, confusion and frustration that mothers feel, can be intense and this is the ground on which the relationship with the paid childcare worker is built. These emotions are 
particularly strong, not because they are produced by individual desires or interests but because they are produced by social forces. They carry the weight of gender inequality in society as a whole, not just the organization of tasks within a single family. The domestic worker is employed to solve the impossible conundrum that working mothers face, whilst being herself a product of it and often experiencing frustrations and anxieties about the care of her own children. The result, unsurprisingly perhaps, is that relations between domestic workers and female employers can be fraught, complex and ambivalent (see for example Pratt 2003, 2004).

A stance which understands childcare to be a social rather than an individual responsibility would relieve the guilt of mothers, allowing them to have more appreciative relationships with carers and to reconsider both the meanings and value of 'care'. Academics and activists who are concerned about care workers need to challenge the idea that individual mothers - or even individual families - are responsible for care and to recognise it as a social good (Tronto 2006), a good that all people have equal rights to. Care is not delegated by mothers to paid carers, but is delegated by society to mothers.

\section{References}

Bikova, M. 2010. The Snake in the Grass of Gender Equality: Au Pairing in Women-Friendly Norway. In: Widding-Isaksen, ed. Global Care Work: Gender and Migration in Nordic Societies. Lund, Nordic Academic Press. pp. 49-68.

Búriková, Z. and Miller, D. 2010. Au Pair, Cambridge: Polity Press.

Busch, N. 2010. UK Migration Regimes, Commoditized Care of Children in Private Homes in London and the Effects of Informality. Paper presented at the Royal Geographical Society Annual Conference, London, $1^{\text {st }}-3^{\text {rd }}$ September 2010.

Cox, R. 2006. The Servant Problem: Domestic Employment in a Global Economy, London: I.B. Tauris.

Cheever, S. 2003. The Nanny Dilemma. In: Ehrenreich, B., \& Hochschild, A. R., (eds.) Global Woman: Nannies, Maids and Sex Workers in the New Economy, London: Granta Books, 31-38.

Gregson, N. and Lowe, M. 1994. Servicing the Middle Classes: Class, Gender and Waged Domestic Labour in Contemporary Britain. London: Routledge.

Rosie Cox: Competitive Mothering and Delegated Care: Class Relationships in Nanny and Au Pair Employment

Studies in the Maternal, 3(2), 2011, www.mamsie.bbk.ac.uk 
Hochschild, A.R. 'Love and Gold' in Ehrenreich, B., \& Hochschild, A. (eds.) 2003. Global Woman: Nannies, Maids and Sex Workers in the New Economy. London: Granta Books, 15-30.

Hondagneu-Sotelo, P. 2001. Doméstica: Immigrant Workers Cleaning and Caring in the Shadows of Affluence. Berkley CA: University of California Press.

Lutz, H. 2008. Introduction: Migrant Domestic Workers in Europe' in Lutz, H. (ed.) Migration and Domestic Work: A European Perspective on a Global Theme. Aldershot: Ashgate. pp.1-12.

Macdonald, C. L. 2010. Shadow Mothers: Nannies, $A u$ Pairs and the Micropolitics of Motherhood. Berkley CA: University of California Press.

Mckay. D. 2007. Sending Dollars Shows Feeling: Emotions and Economies in Filipino Migration. Mobilities. 2(2), 175 - 194.

Madianou, M. and Miller, D. 2011. Mobile Phone Parenting: Reconfiguring relationships Between Filipina Migrant Mothers and Their Left-Behind Children. New Media \& Society. 13(3), 457-470.

Parreñas, R. 2001. Servants of Globalization: Women, Migration and Domestic Work. Stanford CA: Stanford University Press.

Pratt, G. 2003. Valuing Childcare: Troubles in Suburbia. Antipode. 35, 581-602

— 2004. Working Feminism. Philadelphia, PA: Temple University Press.

Tronto, J. C. 1993. Moral Boundaries: A Political Argument for an Ethic of Care. London: Routledge.

Tronto, J. 2002. The Nanny Question in Feminism. Hypatia. 17, 2: 34 - 61.

- 2006. Vicious Circles of Privatized Caring, in Hamington, M., and Miller, D., eds. Socializing Care: Feminist Ethics and Public Issues, Lanham MD: Rowman \& Littlefield. pp. 3-26.

- 2011. Caring About Care Workers: Caring Solutions to an Issue of Global Justice. In: Rianne M., \& Robinson, F., eds. The Global Political Economy of 
Care: Integrating Ethics and Social Politics. Vancouver: University of British Columbia Press.

Uttal, L. 2006. Making Care Work: Employed Mothers in the New Childcare Market. In: Bose, C.E Litt, J.S., \& Zimmerman, MK., eds. Global Dimensions of Gender and Carework. Stanford CA: Stanford University Press. pp. 217-225.

Widding-Isaksen, L. 2010 (Ed.). Global Care Work: Gender and Migration in Nordic Societies. Lund: Nordic Academic Press.

Williams, F. and Gavanas, A. 2008. The Intersection of Childcare Regimes and Migration Regimes: A Three-Country Study. In: Lutz, H. eds. Migration and Domestic Work: $A$ European Perspective on a Global Theme. Aldershot: Ashgate. pp. 13-28.

Zechner, M. 2010. Global Care and Finnish Social Policy in Widding-Isaksen, ed. Global Care Work: Gender and Migration in Nordic Societies. Lund: Nordic Academic Press. pp. 173-194. 
iMacdonald (2010 p.23) traces this philosophy in parenting manuals to the mid 1990s when the first waves of data from the National Institute of Child Health and Human Development's Study of Early Child Care and Youth Development were released. The press coverage of these findings, if not the study itself, suggested that all children not cared for by their mothers were at risk of psychological disorders. The research that had looked at Romanian orphanages was interpreted by the press as applying to the children of all working mothers.

ii In the UK there is no tax deduction for childcare costs unless childcare vouchers are purchased through a workplace scheme and used to pay for formal care so for nanny employers the gross pay of the nanny has to be smaller than the net pay of the employer for it to seem logical to take someone on. In some countries employers get tax breaks on childcare costs and in Norway the state pays a cash benefit to parents if their children do not attend kindergarten which can be used to pay private child carers (Bikova 2010). Similar schemes exist in Finland and Sweden and in Finland a 'domestic help credit' tax rebate is also available to cover the costs of employing people to do cleaning, renovations or care work (Zechner 2010).

Rosie Cox: Competitive Mothering and Delegated Care: Class Relationships in Nanny and Au Pair Employment

Studies in the Maternal, 3(2), 2011, www.mamsie.bbk.ac.uk 